\title{
Rawlsian Constructivism: A Practical Guide to Reflective Equilibrium
}

\author{
Eric Brandstedt ${ }^{1}$ (D) Johan Brännmark ${ }^{2}$
}

Received: 26 May 2019 / Accepted: 10 April 2020 / Published online: 11 May 2020

(c) The Author(s) 2020

\begin{abstract}
Many normative theorists want to contribute to making the world a better place. In recent years, it has been suggested that to realise this ambition one must start with an adequate description of real-life practices. To determine what should be done, however, one must also fundamentally criticise existing moral beliefs. The method of reflective equilibrium offers a way of doing both. Yet, its practical usefulness has been doubted and it has been largely ignored in the recent practical turn of normative theorising. This paper offers a complementary methodology to the method of reflective equilibrium, referred to as Rawlsian constructivism, which brings forth its practical merits. With the support of Rawlsian constructivism, the method of reflective equilibrium becomes a tool for public reasoning about practical problems which aims to facilitate shared solutions. The process of reflective scrutiny is used, not in the search of moral truth, but rather to highlight what stands in the way of solutions to problems agents face in different domains of social life. The practical value lies in scrutinising reasons for action that are taken for granted, explicating new rationales for action and highlighting neglected points of agreement. The paper exemplifies this approach with a process of justifying individual obligations to combat climate change. Normative theorists who share the practical agenda have correctly noted the importance of bottom-up investigations of subject domains. This paper argues that the next step should be to utilise this version of the method of reflective equilibrium to explore the potential for morally progressive solutions to these problems.
\end{abstract}

Keywords Reflective equilibrium · Rawlsian constructivism - Problem formulation · Methodology $\cdot$ Practice-dependence

Eric Brandstedt

eric.brandstedt@fil.lu.se

Johan Brännmark

johan.brannmark@mau.se

1 Department of Philosophy, Lund University, PO Box 192, 22100 Lund, Sweden

2 Department of Global Political Studies, Malmö University, Kultur och samhälle, 20506 Malmö, Sweden 


\section{Introduction}

Many of those working in practical ethics and political philosophy want their work to make a practical difference, perhaps even that it contributes to a better world. One way to realise such an ambition is by applying moral principles to real and concrete practical problems and to deduce relatively specific action-recommendations. The clearest advocate for such an approach is Singer (e.g. 2011), who throughout his career has elaborated on the implications of utilitarianism for questions such as if and when abortion is right, whether there are individual obligations to help the global poor, and whether civil disobedience is justified. Others have adopted similar approaches to political problems, such as just distributions of resources or just war (e.g. Cohen 2008; Fabre 2012; cf. List and Valentini 2016: 543-544).

This top-down approach to practical philosophy has, however, been subject to extensive criticism over the past decade or so. Based on partly different but overlapping methodological discussions, this tradition has been criticised for being practically irrelevant (see e.g. Mills 2005; James 2005; Williams 2005; Sangiovanni 2016). The traditional way of working, these critics claim, is disengaged from real-life practices and fails to address existing relations of power and domination. Ideal theories of justice, legitimacy and democracy, they say, fail to guide action and do not address concrete injustices agents face in the real world. In these discussions an alternative ideal of practical difference-making has emerged. Normative theorists should contribute to a change of the practical reality by taking it as their point of departure. Practical relevance is not just about being specific in one's action-recommendations. Rather, one must understand the point and purpose of politics and other more specific practices to effectuate change. Practical reality must be reformed from within, through non-ideal theories of justice, political realism and practice-dependent or interpretive methods.

But if the objective is to change practical reality for the better, it seems one cannot just study it in detailed manner. Surely, one should not just accept any normative belief, judgment or practice that happens to exist, however deeply unjust it may seem (see e.g. Erman and Möller 2013, 2015; Finlayson 2017). Normative theorising requires some critical distance from the status quo; the normative theorist must expose all beliefs, judgments and practices to critical scrutiny. Otherwise normative theorising would be apologetic and uncritically accepting what may be a morally rotten status quo. The practical methodologies presented so far are incomplete. They give reasonable ideas about how practical relevance should be sought, but falter in their critical justificatory part.

It is necessary to measure the results of bottom-up investigations of relevant practices against critical standards of independent moral principles. Thus, exactly what the method of reflective equilibrium sets out to do. Strangely enough, this method has hardly been mentioned in the methodological turn of normative political theory. This is particularly surprising considering that the one who brought the method into practical philosophy, John Rawls, otherwise has been at the centre of these discussions. Andrea Sangiovanni (2008: 149) notes that the 
interpretivist method he defends 'only begins [...] the search for reflective equilibrium'. But then what? An adequate description of practical reality may (very likely) be a necessary prerequisite for changing it in a desirable direction, but how should then the critical scrutiny proceed? As argued by Eva Erman and Niklas Möller (2015: 535-536), practice-dependent methods may need to be complemented with something like the method of reflective equilibrium. The reason why this has not happened, why the method of reflective equilibrium has been overlooked in these contexts, we submit, is that its potential as a practical methodology has been neglected.

In this paper, we aim to remedy this situation by presenting a practical guide to reflective equilibrium. We argue that the method of reflective equilibrium can be used to strike the desired balance between practical relevance and thorough criticism, and that it is thereby an appropriate method for doing practical ethics. We believe that when Rawls first developed the method, he intended it to be part of a wider practically oriented methodology. According to this methodology, which we refer to as Rawlsian constructivism, the method of reflective equilibrium is a tool for social reasoning about practical problems, such as how to distribute scarce resources in different domains of practice, which facilitates shared solutions. The process of reflective scrutiny is used, not in search of moral truth, but rather to highlight what stands in the way of solutions to problems agents face in different domains of social life. The practical value lies in scrutinising reasons for action taken for granted, explicating new rationales for action and neglected points of agreement. Rawlsian constructivism is the methodology detailing how this is done. It adds to the iterative process of reflective scrutiny a problem formulation, that is, an outline of the clashing judgments in need of solution. It further supports the process of justification once underway by various heuristics and decision-making procedures, provisional constructs which concretise the process of justification. Although Rawls's methodology has had a great impact on the field, few scholars have explored this combination of reflective equilibrium and constructivism.

We will proceed as follows. In "The Method of Reflective Equilibrium and its Practical Value" section, we begin with a critical discussion of the received interpretation of the method of reflective equilibrium. We argue that it has won its dominant position by losing its practical edge. It has come to be understood as just a general coherentist epistemology. Although coherence is an important criterion for theory choice, also in practical ethics, it is hardly in itself a guide to practical differencemaking. We thereafter return to the package of methodological ideas complementing the method of reflective equilibrium in Rawls's original presentation of it. Although some reconstruction of Rawls's discussion is needed, our aim is not exegetical but to extract the resources needed to articulate this alternative. Throughout his career, Rawls advanced potentially useful methodological complements to RE, but unfortunately stated them ambiguously and deeply entangled in his particular application of 'justice as fairness'. In "Rawlsian Constructivism" section, we disambiguate and disentangle these methodological ideas, which we refer to jointly as Rawlsian constructivism, and explain their influence on the process of moral justification. In "Working as a Rawlsian Constructivist" section, we exemplify what it means to be working as a Rawlsian constructivist. In "The Practical Ambition" section, we discuss what 
should be expected from different processes of justification and in so doing respond to criticism that can be directed towards a practically oriented approach.

\section{The Method of Reflective Equilibrium and its Practical Value}

A cursory review of contemporary discussions in ethics and in political philosophy suggests that Rawls's methodology has had a great impact. The method of reflective equilibrium is more or less standard, and influential commentators claim that it is even an indispensable approach (see e.g. Scanlon (2003: 149); Parfit (2011: 367), and McMahan (2013)). But the method which has had this success is only superficially similar to the justificatory process Rawls proposed and employed. It has a theoretical rather than practical orientation.

According to the textbook version of the method of reflective equilibrium, it is a coherentist method of epistemic justification according to which moral beliefs are justified by being supported by other beliefs (Daniels 2018). The process of reflective equilibrium is understood as working back and forth between particular judgments and general principles seeking mutual support. This idea, however, is relatively empty, and should perhaps primarily be seen as excluding certain foundationalist ideas of justification (cf. Walden 2012). To apply it, complementary ideas are needed. Very often the method of reflective equilibrium is supplemented with the methodological ideals of Daniels's $(1979 ; 1996)$ influential interpretation of wide reflective equilibrium. It is thus understood as seeking to systematise as many moral judgments as possible in an ambition to approximate moral truth. Considered judgments or intuitions about particular cases-e.g. whether abortion is morally permissible, whether killing civilians in war is ever morally permissible, whether human organs may be sold on a market - are justified by subsumption under more general moral principles through which their support is determined. Vice versa, principles are justified by being supported by credible beliefs about particular cases. The theorist should work back and forth between these levels of generality and make mutual adjustments: either give up particular judgments, whose credibility has been undermined by the presence of general principles, or, contrariwise, revise principles in order to accommodate firm beliefs. The process is to be carried on until as wide coherent whole as possible is reached.

Regardless of the theoretical merits of this method, it is not an unproblematic approach and it is doubtful whether it is the best way to proceed in practical ethics (cf. Arras 2007). First of all, the widest set of beliefs over which coherence can be achieved may not be very wide or at any rate far from having a global scope. In particular, if the method is employed in pluralistic societies, full coherence across all moral beliefs is a distant ideal. It is highly unlikely that e.g. pro-life and pro-choice proponents eventually will converge on some unifying principle. To the extent that that is possible, it is likely to come at the cost of action-guidance. If, for instance, such disparate starting points are made coherent by being subsumed under some highly abstract, formalistic principle or a simple disjunction of the two contrary judgments nothing much is gained. Secondly, the relevant question in practical ethics is arguably not what I should believe, but rather what I (or we) should do (although the 
latter of course presupposes an answer to the former). Whether or not the method of reflective equilibrium is the best method in practical ethics is not determined by whether it leads to true beliefs, but rather whether it is a useful tool for dealing with conflicts standing in the way of successful action in different domains of social life. The extent to which theorists find these two worries troubling might certainly vary, and our goal here is not to do a comparative analysis, but at the very least they might make one want to take a serious look at possible alternative approaches to working with reflective equilibrium. Our suggestion here is that an alternative to the standard method can, perhaps somewhat ironically, be found in Rawls's own approach.

That Rawls's methodology differs from the coherentist epistemology now described is perhaps clearest in his later works, in his turn towards political liberalism (2005). But already in 'Outline of a Decision Procedure for Ethics' (1951), he expresses this other ideal of justification which he then elaborates on throughout his career. The most important point of difference is that according to this ideal justification has a practical orientation. He describes it as follows: 'The practical aim is to reach a reasonably reliable agreement in judgment in order to provide a common conception of justice' (1999: 39). With such an aim, the problem of justification only arises in cases of disagreement in judgment. Justification is 'addressed to those who disagree with us, or to ourselves when we are of two minds' (1999: 508). But not even in all such cases: there must, furthermore, be a shared point of departure, 'some consensus' from which it can proceed-'mere proof is not justification' (1999: 508). To justify some conclusion, one must not only show that it follows from a set of premises, but also that those premises are ones we are (or I am, in the individual case) committed to in the first place. The task of a moral theory begins to take form: it corresponds to that of a theory of justice, which is to formulate a conceptual construct that 'tends to make considered judgments of justice converge' (1999: 40; see also 46).

The practical orientation is also reflected in Rawls's designation of the subjects to the process of RE. It is the judgments of practitioners, such as citizens of a state, not those of the theorist, that are in need of justification. The theorist should take the more restrained role of 'the observer', 'who seeks to set out the structure of other people's moral conceptions and attitudes' (Rawls 1974: 7; cf. Rawls 1980: 518). To locate the need for justification among practitioners also makes it a social enterprise. The justificatory process is not, or at least not primarily, an epistemological project aimed at moral truth. The point is to overcome disagreement in situations where agents have conflicting views about what to do-the 'practical social task is primary' (Rawls 1980: 519).

There is accordingly no need for the theorist to fully sort out the epistemology and metaphysics of morality. Rather, 'the further advance of moral philosophy depends upon a deeper understanding of the structure of moral conceptions and their connections with human sensibility' (1974: 6). Moral theory is more akin to psychology and social theory than to the conceptual work prevalent in ethics. By proposing something like a model or thought experiment the theorist should try to unveil the relations between judgments at different levels of generality and suggest acceptable revisions. This involves experimenting with different organising principles. For instance, what if society were organised with the utility principle? What 
guarantee would that leave for individual freedom? What kind of person would exist under such an ideal?

'The central theoretical endeavor of moral theory' is to make comparative studies of different 'well-ordered societies', that is, to compare the consequences of organising society with various normative principles everyone is assumed to comply with (Rawls 1974: 13). Now, obviously this goes beyond the authority of the mere observer: the theorist must play an active and interfering part in the construction and evaluation of model societies, as opposed to that of the passive and distant spectator. He later develops the point as follows:

The aim of political philosophy, when it presents itself in the public culture of a democratic society, is to articulate and to make explicit those shared notions and principles thought to be already latent in common sense; or, as is often the case, if common sense is hesitant and uncertain, and does not know what to think, to propose to it certain conceptions and principles congenial to its most essential convictions and historical traditions (Rawls 1980: 518).

To the extent that the theorist is confident that her own judgments match those relevant to the target problem, the justificatory process could be conducted alone by the theorist, albeit in an empirically informed manner. However, more likely the theorist will need to engage more directly with practitioners in order to make sure that she addresses what are for them relevant problems and proposes solutions that at least have the potential of being shared by them.

\section{Rawlsian Constructivism}

The justificatory ideals seen in the review of Rawls's methodology clearly go beyond what is captured in the textbook version of the method of reflective equilibrium. One might, however, suspect that these additional ideas come from his particular application of the method to questions of political justice rather than that they are a general methodology. But this is not so, we shall now argue. These justificatory ideals can be assembled into a general methodology for how to work with the method of reflective equilibrium in practical ethics. We refer to the resulting view as Rawlsian constructivism and explain its essential elements, as well as ideas naturally associated with it, in what follows. Rawlsian constructivism should not be thought of as a rejection of the received interpretation of the method of reflective equilibrium, i.e. the general coherentist epistemology. It is, however, an essential complement to it for those who share the practical difference-making ambition in practical ethics.

The reason why we call the view Rawlsian constructivism is its affinity to what Rawls first calls Kantian constructivism (1980) and later political constructivism (2005: 89-130). ${ }^{1}$ The construction in question is of bridges connecting normative

\footnotetext{
1 Although this shift reflects an important change in Rawls's theorising (discussed below in the main text), it does not affect the general constructivist idea. This justifies dropping the narrowing prefixes ('Kantian' and 'political').
} 
ideals and shared moral sensibilities of individuals. In the real-world, individuals are often locked in deep conflicts about what is right and good, but Rawlsian constructivism assumes that they often also share common ground. The task of moral and political philosophy is to explicate this consensus, which may not be immediately apparent as it is obscured prejudices, passions and ideology. Thus, normative ideals are essentially related to different conceptions of the person. It is by giving a picture of human persons related in an ideal society that we can assess normative ideals about how real-world individuals ought to act.

Rawls explains the core idea of constructivism as follows: it is 'to establish a suitable connection between a particular conception of the person and the first principles of justice, by means of a procedure of construction' (Rawls 1980: 516). The resulting three-part relation is the core of constructivism: 'a conception of the person' related to 'the first principles of justice' by means of 'a procedure of construction'. These parts, or 'model-conceptions', are general notions (Rawls 1980: 535). They can take the form of justice as fairness: a conception of the person as free and equal related to the two principles of justice by means of the original position or, for instance, of Kant's moral theory: the conception of the person as autonomous related to universal laws by means of the categorical imperative. What is important is establishing a connection between a normative ideal and a particular conception of the person, such that it is an ideal for someone which real-life people can identify with. The challenge is to find a reliable method for doing so. Although these ideas are still somewhat unclear, they are significant and can be sharpened into important complements to the method of reflective equilibrium.

The motivating idea of Rawlsian constructivism is that normative ideals have a practical function: they guide agents in situations in which there is disagreement or uncertainty about which actions to take towards a successful solution of that predicament. The point of formulating and justifying normative ideals is given by the practical-social function: it is to evaluate and seek to improve solutions to action problems. On this basis, Rawlsian constructivism puts forward two related methodological ideas that inform the process of justification: (1) that one should not expect a unison solution to all problems, but rather be pluralistic; and (2) that proposed solutions must be evaluated on a relatively concrete level of description at which real-life agents can relate to them and understand how they connect to problems they face. Both these tenets relate to the conception of justification which Rawls espoused, according to which there is a crucial difference between proof and justification. In order to engage in justification of what ought to be done, one must first establish a shared point of departure.

Thus, we come to the first element of Rawlsian constructivism. It is that prior to the iterative process of working back and forth between different levels of judgments, one should specify those judgments in a problem formulation. If the justificatory process is to be purposeful, the subject matter must be defined. For example, in a justificatory process aimed at formulating principles for the just distribution of social goods in society, not every normative judgment will be relevant to consider. Those having to do with what an individual deserves may have no bearing on this. Similarly, in a justificatory process aimed at regulative ideals for fair business exchanges or for combatants' obligations to civilians in a state 
of war, one must define the judgments relevant to those domains. The justificatory process, accordingly, begins with a problem formulation which encircles a subset of all possible judgments, namely those in need of justification. This is primarily a matter of formulating what is the relevant problem, but it also involves consulting a minimal standard of what is a reasonable judgment to consider in a process of justifying moral and political ideals. One may, for instance, need to exclude normative judgments claimed to be immune from critique as the process of nipping and tucking otherwise could not proceed. Beyond that, the practical aim informs the choice: the problem formulation singles out some judgments because they are in tension with one another; any action they recommend would be unstable and sooner or later undermined. Rawls, for instance, searches for principles of justice for free and equal persons because it is unclear how persons thus described can submit to the authoritative rules of a society. If only in vague outline, the justificatory process should then begin by describing a typical situation in which there is a clash of judgments. The point is that the theorist proposes that the end-point equilibrium should be sought for agents or in situations thus understood, rather than for all agents and all situations.

The problem formulation is not fixed once and for all, but rather something that must be constantly updated as the method of reflective equilibrium proceeds. An example of this is how Rawls takes on board 'the fact of reasonable pluralism', that is, the persistent normative disagreement that must be accepted as a permanent condition in liberal societies (2005: 36). Given this fact, the kind of considerations Rawls allowed himself to use in his earlier work, drawing on substantial normative ideals ('comprehensive moral doctrines'), are now off the table. Instead, the basic structure of a liberal society needs to be secured in 'an overlapping consensus' on its political values, without presupposing any particular comprehensive moral doctrine (2005: 9). The inclusion of reasonable pluralism, in other words, steers the justificatory process in a particular direction. The idea of 'public reason' narrows its scope from justice in general to 'questions of constitutional essentials and basic justice' (2005: 214). Whereas previously any kind of consideration, including those of all standard moral theories, was admissible, now only a more limited set of political values are relevant to consider.

Oftentimes a better understanding of what is at stake in a particular situation can be gained by examining solutions to what should be done about it. Seemingly intractable disagreements may be overcome or reduced by discovering points of agreement, such as that everyone agrees on the need for a principled, reasoned, and reflectively acceptable solution. Perhaps everyone will also agree that the solution should be stable or certain core values be promoted. This is the stuff with which a more precise problem formulation can be outlined and it is essential for any progress to be made. That is why the theorist must attempt to 'articulate and make explicit shared notions and principles'. If agents cannot agree on the content of moral principles, which is what characterises certain hard cases, then there remains the hope that by presenting, comparing and scrutinising their underlying structures things will move forward. Such reflection may reveal similarities and so explicate points of agreement. 
The second element of Rawlsian constructivism is a way of concretising the evaluation of normative judgments and principles. This is done by two theoretical constructs. The first is the use of conceptions of the person as tools for assessing what is at stake and what is to be done. The problem specified in the problem formulation is not addressed as an abstract clash of judgments, but as someone's obstacle to action. Why formulate it in person-oriented terms? One reason is that these are the kind of problems we are interested in in practical ethics. Practical ethics should guide agents acting and interacting in different domains of social life. To do so, the solutions it offers must relate to these agents and to their view of themselves. Justification is addressed to those who are in disagreement and it aims to lead them from the respective starting points towards a shared solution. To give an adequate description of the relevant situation involves describing what matters to the agents situated there. The use of conceptions of the person also serve a pedagogical function in allowing us (theorists as well as practitioners) to really judge the implications of abstract normative principles. This is relevant also once the back and forth movement of the method of reflective equilibrium proceeds. General moral principles are used to scrutinise what should be done in the specified situation, but instead of considering their appeal in the abstract, they are assessed by scrutinising the implications that they would have were they to be complied with there. Thus, what would e.g. a rule utilitarian or Kantian be committed to in the kind of situation described in the problem formulation? Moral theories and principles are evaluated as prescriptions of ideal persons, that is, patterns of actions associated with fully complying with the theory or principle in question. The use of conceptions of the person is a methodological tool which facilitates a purposeful process of justification and allows cognitively limited beings as us to take a stand on whether we are prepared to accept the implications of abstract moral principles. The ambition is to map out a path from the tension-creating conception of the person of the problem formulation to a renegotiated one.

The second way in which the justificatory process is connected to a more concrete level of concerns is through the use of what Rawls calls procedure of construction, which falls under the general category of thought experiments and models. The procedure of construction can establish a link between the conception of the person, expressed in the problem formulation, and normative principles. Rawls (1999: 19) describes his procedure of construction, the original position, as an 'expository device', which sums up the conditions of free and equal citizens and connect them to the main 'traditional conceptions of social justice' (1999: 16). Like any model, it is a simplification and abstraction: it describes an ideal world (e.g. 'a well-ordered society') populated by model persons (e.g. 'contracting parties'/' citizens of a wellordered society'). But it is a model for real people, as they should be able to 'enter the original position, so to speak, simply by following a certain procedure, namely by arguing for principles of justice in accordance with these restrictions' (1999: 17). The model should not only be able to display justificatory relations, but also be useful in facilitating the justificatory process. In this heuristic-like function, the model can be rough-and-ready and be revised and elaborated on as the need arises. But it cannot be developed in just any direction: it is constrained by the problem formulation and by the requirements for what count as a successful simulation. Beyond the 
original position, other examples might be the categorical imperative, which can be used to expound Kantian ethics, and the impartial spectator, which can be used to bring forth the implications of a utilitarian ideal. Regardless of which specific model is used, the point of it is to clarify the relationship between the conception of the person described in the problem formulation and the normative principles proposed as solutions to it. Perhaps there are other ways of doing this too, but the use of a procedure of construction is at least a clear example of how to proceed. It should also be noted that what is constructed through Rawlsian constructivism is not moral truth or standards of correctness, but rather something like a shareable standpoint from which individuals can see themselves and their surroundings.

Another important feature of Rawlsian constructivism concerns the fact that in order to specify a relevant problem formulation, it is necessary to somehow consult social reality. This can be done by making the method of reflective equilibrium more of a joint activity that the theorist engages in together with relevant practitioners rather than alone. Alice Baderin (2017) distinguishes three ways in which this can be done: by using judgments or intuitions of relevant practitioners as input, or by conducting the process of justification together with practitioners, or by letting practitioners formulate the normative principles, i.e. the solutions to the problems they face. The most common version of the method of RE is private in all of these respects, in the sense that no external input is used; the theorist uses her own particular judgments and normative principles from the tradition to guide the process. ${ }^{2}$ But more public versions have been proposed, which either take intuitions from relevant practitioners as input (e.g. Van Thiel and Van Delden 2010) or are conducted together with affected parties (e.g. Wolff and de-Shalit 2007; Doorn 2009). Given the practical aim of Rawlsian constructivism, it is natural that the process of justification should be somehow public. The input data need to be gathered by engaging in investigations of different target domains. ${ }^{3}$ In the case of business ethics, by looking for shared convictions essential to domain of business and commercial exchange, and for morality of war to notions relevant in that domain, and so on. The possibility of the theorist consulting her own intuitions is not precluded, but a case must then be made for their fidelity to the target domain. More credibly, there is a need for an empirical investigation of the domain in question. The practical aim of Rawlsian constructivism is a presumption against relying singlehandedly on one's own judgments.

Whether or not the process of justification should be more robustly public by being conducted together with relevant practitioners depends on what more specific result that is intended to come from it, but that is left open by Rawlsian constructivism. Two more specific objectives can be distinguished, both of which are practical but give more or less direct action-guidance. Either one can take the process

\footnotetext{
${ }^{2}$ This is also the version which Rawls seems to have worked with in Theory: 'the views of the reader and the author are the only ones that count. The opinions of others are used only to clear our own heads' (1999: 44).

${ }^{3}$ Similar strategies are proposed by e.g. Buckley (2010) and of course by the practice-dependent theorists referred to above.
} 
of justification to have the aim of mapping out possible points of agreement and disagreement in some relevant subject area, or more ambitiously as contributing to actual conflict resolution. If it is the first objective that the process is aimed at, then it is warranted that it is carried out more privately (although still with empirical input), whereas if it is aimed at the second objective, then the theorist should probably carry out the process of justification together with relevant practitioners (cf. Wolff and de-Shalit 2007). One should, however, moderate one's expectations also about the latter kind of process; perhaps, it is reasonable to expect some convergence, but not a full consensus (cf. Doorn 2009). Either way, the more overarching aim is to justify action-guiding normative principles for the conflictual conception of the person specified in the problem formulation, such that were real agents to identify with it, they could use these principles to resolve the inherent conflict.

In summary, Rawlsian constructivism focuses the justificatory process on situations in which practitioners need to agree. It gives the theorist the task of specifying or determining starting points for and guidelines along the way. What is more, the constructivist idea brings out the need for specifying a procedure of construction, which connects abstract normative ideals to more concrete and particular conceptions of the person. This promises to advance the justificatory process. Not because there cannot be disagreement about conceptions of the person-there can be, although it is perhaps less likely than disagreement about the truth of moral theories-but because constructivism provides additional information. It shifts the focus from the content of normative ideals to the structural features of acceptable agreements, from comparing judgments to comparing judges, i.e. ideal conceptions of the person produced by complying with different moral principles, and so facilitates continuing discussion. For a justificatory process situated in imperfect conditions, as is so often the case in practical ethics, this may be the only way forward.

These observations suggest that Rawlsian constructivism is distinct from the metaethical and normative constructivisms more commonly discussed (see e.g. Korsgaard 2003; Street 2008; Ronzoni and Valentini 2008). It is a methodological position that is not primarily about the reasons we have as agents, but about what we should do as normative theorists. ${ }^{4}$ It is important to note that Rawlsian constructivism does not reject the core method of justification known as reflective equilibrium-justification is still sought by working back and forth between more or less general moral judgments-but instead complements it with a practical focus. We believe that this outlines a plausible reading of Rawls, but more importantly, we find it a fruitful way of reading Rawls. In the end, nothing will strictly depend on this interpretation being correct, although if it is, it certainly strengthens our claim that the form of constructivism that we present here is a viable methodological approach (because Rawls can then be taken as a good example of how one can work in this way).

\footnotetext{
${ }^{4}$ Brink (1987: 75-80) and Ebertz (1993: 208-210) also discuss a methodological construal of Rawls's constructivism. See also Brännmark and Brandstedt (2019).
} 


\section{Working as a Rawlsian Constructivist}

The practically oriented approach to normative theory recommended by Rawlsian constructivism is arguably employed to some extent already in parts of practical ethics, in particular in domains in which ethicists work closely together with practitioners, such as in bioethics (see e.g. Arras 2016). To illustrate its more general applicability, and to further disentangle it from Rawls's particular application, we will now apply it to a normative issue not clearly linked to a specific practice. That is, the question about what obligations, if any, an individual has in relation to climate change.

To approach this issue as a Rawlsian constructivist one should first investigate different views about what individuals should or should not do in relation to climate change. This involves describing what actions and behavioural patterns that are typically relevant in the context and the goods around which such transactions revolve. The actions in question could be e.g. whether to eat meat or a plant-based diet, whether to pay more for renewable energy or for an electric car, whether to avoid flying, and perhaps reproductive choices about how many children to have. In and around these actions a plurality of different goods and values constitute the tension which prevents an individual from making an informed and reasonable decision about what she should do in relation to climate change. The conflicts of interests also prevent individuals from successfully engaging in joint action in this context. These goods, values, or stakes should be specified. In this case this may involve listing diverse goods, such as money, time, greenhouse gas emissions, energy, personal relations and preferences. Although the starting point for this investigation is particular judgments, the aim should be to arrive at an adequate description of the typical conflicts, which may require some generalisation. This involves determining what counts as the relevant conflict, as well as what normative judgments are minimally reasonable. In the present case, this may for instance lead one to exclude judgments based on a denial of the reality of anthropogenic climate change. This is partly because the relevant problem formulation should define a common point of departure and in this case factual disagreement about the phenomenon in question may be considered the absence of that. It is also because the very idea of determining whether individuals have obligations in the light of climate change presupposes that there is such a thing as climate change. It is important to note that although the problem formulation thereby excludes some moral judgments, they are not excluded for moral reasons but because they are not relevant to the practical problem addressed.

With the results of this investigation, the theorist specifies a problem formulation, which in this case will contain, on the one hand, judgments such as it being wrong to contribute to the unfair and harmful consequences of climate change, and, on the other hand, judgments such as that it is unfair that an individual should make sacrifices when others do not act and that it is consumers' right to buy products offered on the market and that it is unfair to forego an investment in a diesel car as it was bought under the assumption that it would last for a decade or two, and so on. The task thereafter consists in proposing organising 
principles and critically examining both these and the particular judgments, seeking a reflective equilibrium. The process of justification is a movement from a thinly described starting point towards a more definite set of considered judgments about what should be done.

The problem formulation focuses the process of justification, but it is also updated as more is learned about what is the relevant problem. Along the way, different conceptions of the person are used as points of evaluation and normative principles are scrutinised on a relatively concrete level of description through the use of various heuristics. Beneath the conflicting judgments of the problem formulation one may, for instance, discover some common ground: perhaps that one should be reasonable, care about the consequences of one's actions on geographically and temporally distant others, and be willing to make small sacrifices of self-interest for moral reasons conditionally on others doing so too. If this is so, one may continue by asking whether such a person would be obliged to do something about climate change. An answer is sought by testing whether various moral principles can support such a conclusion. The task consists in showing that a person facing this particular kind of problem should adopt a certain moral principle. The moral principle is justified by showing that it best fit, match or account for the considered judgments in the problem formulation. The principle must, in other words, be such that the agent who engages in this specific process of justification can come to accept it as reasonable after due deliberation. A moral principle according to which individuals have no moral obligations to distant strangers would for instance be rejected here.

To further focus the process of justification and to facilitate a solution to the problem, the theorist can propose a procedure of construction or otherwise seek to evaluate the moral principles on a relatively concrete level of description. This could be done by drawing on some already established model of moral reasoning, such as the original position or the impartial spectator, but may also involve reformulating the conflict in terms of a thought experiment to illustrate its main stakes. And again, the use of conceptions of the person is a way forward. One may, for instance, imagine an individual who only cares about not harming anyone else and ask questions about what actions such an individual could undertake in good faith, or alternatively, an individual who only cares about individual autonomy and ask questions about what she would have to do to not compromise anyone else's autonomy in relation to climate change. The point is not to uncover what moral principle is most plausible in general, but to explore the implications or rational commitments of various moral principles for the case at hand. In the present case, the processes of justification can be expected to increasingly focus on what is the relevant conflict with regard to individual climate obligations by defining increasingly contextual moral principles as well as specific moral judgments. In the end, the considered judgments at stake may for instance be 'one should not eat meat because of climate change' and 'one should not fly because of climate change' and the question be whether some contextual principles can ground such judgments. We would thus have ended up with a richer description of the person in question and more specific justificatory problem with a determinate answer.

The point of engaging in this reflective scrutiny, according to Rawlsian constructivism, is to overcome the existing disagreement or division which is characterised 
in the problem formulation to promote action and stable solutions. One may, for example, note that individuals today are torn between different ideas about what they should or should not do in the light of climate change. Some behaviour is criticised as immoral; some criticism is found unfair. By scrutinising moral principles in this particular context, the process of reflective equilibrium can move beyond surface level clashes and divisions and make explicit the rationale behind these claims and judgment, as well as to explore what rational commitments they come with. This is practically significant in different ways. It can lead to insights that intuitive judgments lack a moral ground and thus should be given up. It can also highlight how two seemingly incompatible judgments share a moral ground on the basis of which the differences can be traced to different empirical assumptions. It can also lead to awareness about rational inconsistencies in the form of two beliefs being incompatible. In the present case an example may be the conviction that individuals have an unrestricted right to choose what to eat, which could be shown to be incompatible with a minimal care for other people's basic needs by exploring the implications of individual freedom in a globally interconnected world.

\section{The Practical Ambition}

After having now presented Rawlsian constructivism, the question remains whether the justificatory processes it recommends is likely to realise the practical differencemaking ambition and at the same time offer a critical scrutiny of taken for granted assumptions. Ultimately such a proof should be sought in a more detailed application of the method than we could provide here. What we can do now is to further emphasise the distinct qualities of this approach. One thing is its focus on practical value for real-life agents. The practical value is partly located in the potential to overcome reasonable disagreement and converge on certain intentions or plans of joint action as a result of the process of reflective scrutiny. Such local equilibria, where actors converge on what reasonably must be done, are more realistic than the global equilibrium otherwise sought. Furthermore, there is practical value also in the search for these local equilibria, even if they are not fully achieved. To the extent that agents locked in disagreement can learn more about what stands in the way of solving the problems they face, this is likely to increase the chance of an eventual conflict resolution.

Rawlsian constructivism has a certain affinity to other practically oriented methodologies in that it accepts that there is an important difference between applying an independently justified moral principle and justifying contextual moral principles in a bottom-up fashion. The search for the best principle to solve some practical problem will involve making difficult compromises, assessing the relative importance of different moral ideals and giving up certain moral convictions. This goes far beyond just examining the empirical preconditions for the application of an already independently justified moral principle. But unlike some of the alternative practical methods (e.g. Sangiovanni 2016), it does not presuppose a teleogical view of practical reality according to which the normative theorist must understand the point and purpose of various practices. It offers another understanding of doing practical ethics, that is, to 
search for solutions to practical problems which have the potential of being accepted by real-life agents locked in disagreement.

Having said that, someone may not be convinced that Rawlsian constructivism makes an important contribution to the method of reflective equilibrium or that the practical focus changes much in the traditional understanding of the process. In response to this, we should first repeat that the idea is not to reject the method of reflective equilibrium, but rather to apply it in a more practically useful way. Rawlsian constructivism understands justification as sorting out relatively concrete practical problems and working towards their solutions rather than as a search for moral truth. This should not be thought of as the master method which everyone must follow in practical ethics. Rather, it is utilising the tools of reflective equilibrium to better understand practical problems and to shed new light on what is needed to solve them. Other approaches, such as casuistry, pragmatism and feminism, do so too (see e.g. Arras 2007). And the method of reflective equilibrium also in this embodiment has its limitations. Certain value conflicts may not be amenable to reasoned solutions. If, for example, a disagreement between two parties runs so deep as if they lived in different worlds, then there may be no common ground on which shared solutions can be formulated. Perhaps this is the case with pro-life and pro-choice proponents or those deeply worried about the effects of climate change and those denying its reality. But it may also turn out that once we come to better understand these problems and the relevant moral and nonmoral beliefs involved, we will come to see what stands in the way of their solution.

If and when a practical problem has been sorted out and some considered judgments justified for what to do in a case at hand, the question remains whether these judgments and the principles justifying them are valid more generally, in other situations. Thus, for instance, if it turns out that one can establish a link between the judgments of the problem formulation pertaining to individual climate obligations and the considered judgment that one should not eat meat because of climate change via some climate-specific moral principles, then someone might claim to thereby having discovered the moral fact that one should not eat meat. But of course, this does not follow: one would need to provide additional arguments to draw such a conclusion and to know that this is what one should do all-things-considered. To meet the practical aim set by Rawlsian constructivism, a process of justification stops at a partial reflective equilibrium, i.e. a systematic organisation of a subset of all moral judgments. This should not prevent one from then continuing the process of justification and seek to systematise different domains of practice or even the whole moral landscape, but these are not the ambitions of Rawlsian constructivism (see also Brännmark and Brandstedt 2019).

A critic might say, however, that by anchoring the process of reflective equilibrium in particular judgments, Rawlsian constructivism sets up an insufficiently critical or conservative justificatory process. In response to this, two things should be emphasised. First, if one is at all interested in addressing practical moral conflicts real-life agents face in the here and now, there is no way around taking certain positive judgments as points of departure. Even if the domain in question is characterised by some moral judgments which we will later consider false or even perverse from a more advanced moral position, there is still a need to decide which revisions 
to make now in order to deal with existing conflicts. A comparison can be made to the method of explicating concepts (Brun 2017). To successfully explicate some concept, certain criteria have to be met and 'similarity' is one of them. When the initial pre-theoretical concept (e.g. fish) is replaced by a more exact concept (piscis), the relation between the two must be such that they are sufficiently similar in some sense, otherwise the process will just have changed the subject matter. Similarly, according to Rawlsian constructivism, one might say that a similarity condition obtains between the pre-theoretical judgments of the problem formulation and the resultant considered judgments, as one otherwise would have failed to address the practical problem targeted. Exactly how to specify this condition is difficult, but preliminarily one might say that the considered judgments must maintain enough extensional overlap with the pre-theoretical judgments and maintain clear-cut cases (cf. Brun 2017). Rawlsian constructivism gives guidelines for how existing conflicts between normative judgments can be handled and a more reflective-albeit provisional-moral position can be achieved.

The second point to emphasise is how the use of moral principles provides a critical standard. Rawlsian constructivism does not preclude the consultation of practice-independent and general moral principles, such as those of utilitarianism or egalitarianism. It is after all not replacing but complementing the method of reflective equilibrium. After the theorist has outlined the problem formulation, general moral principles are used to systematise and scrutinise the particular judgments described. Yet, the expected output of this process is contextual principles-what from a more top-down process may be thought of as mid-level principles or rules of regulation-that deal specifically with the problem addressed and from which relevant considered judgments can be deduced. The reason for why the end-product is not entirely general is that the process aims to resolve a specific obstacle to action for specific agents. Still, the provisionally fixed points in the problem formulation are tested against principles with application in a wider set of situations than that of any one particular judgment. Particular judgments may need to be given up or be dismissed as irrelevant after having consulted such principles. Even if in this kind of justificatory project, we are only interested in a subset of all the implications moral principles have, namely in the relevant class of situations, principles are used and provide an independent standard from which particular judgments can be assessed.

But, then, what about the criticism of ideal theory referred to at the outset of this article? Someone might say that regardless of where the justificatory process starts - however well it is rooted in a relevant problem formulation-if it consults ideal normative principles, it will eventually drift away towards some abstract ideal unrelated to the concerns of real-life agents. The response to this critique has in a way already been given. The problem formulation ensures that whatever normative principles the process of justification ends up with will be sufficiently connected to the specific problem addressed. The justificatory ideal which motivates Rawlsian constructivism can indeed be seen as an answer to the critique against ideal theory: ideal normative principles can guide action if and to the extent that they establish a connection between particular normative judgments real-life agents hold and considered judgments they ought to hold. Action-guidance is sought by establishing a 
bridge between these two sets of judgments through contextual normative principles. Rawlsian constructivism supplies the tools for constructing such a bridge.

\section{Conclusion}

We have addressed those practical ethicists who share the ambition of making a practical difference. The extensive methodological discussions in normative political theory of the last decade or so have emphasised the importance of studying practices one wants to reform in order to map out what is at stake, what agents agree and disagree about. From the perspective of some parts of practical ethics, such as bioethics, there is almost a consensus that such a mapping is necessary. However, normative theorising of course is not just descriptive. It is also about questioning, challenging and occasionally rejecting ideas about what is right and wrong. For those who accept that moral judgments or beliefs about particular cases have some role in the justificatory processes, the obvious method of justification is that of reflective equilibrium - so obvious that it is difficult to imagine an alternative approach.

Although the method is often used in practical ethics, its potential as a practically oriented method of justification has been neglected, at least in normative political theory. One reason for this is that the method in its received interpretation does not seem conducive to practical difference-making. We have, however, argued that a more practically oriented version of it can be found in Rawls's wider methodology. The core idea of Rawlsian constructivism is to utilise the process of reflective equilibrium to advance shared solutions to practical problems agents face in social life. The practical value is central. Theoretical constructs are used as heuristics to assist a solution-oriented reasoning among agents locked in disagreement. The ambition is not to systematise the whole of morality in a full reflective equilibrium, but to contribute to a more considered view about what should be done in social reality as it is.

Acknowledgements Open access funding provided by Lund University. Eric Brandstedt's work was supported by the Swedish Research Council under Grant Number 437-2014-6692. Johan Brännmark's work on this paper has been enabled by a position as Research Fellow granted by the Royal Swedish Academy of Letters, History, and Antiquities. Earlier versions of this paper were presented at the Higher Seminar in Practical Philosophy at Lund University, 'VIII Braga Meetings on Ethics and Political Philosophy' in Braga, 'Filosofidagarna 2017' in Uppsala, and the Research Seminar in Practical Philosophy and Political Theory at the University of Gothenburg. We thank the participants of these events for their comments. We are also grateful to those who helped us with written comments on earlier versions of the paper: Mollie Gerver, Olof Leffler, Frits Gåvertsson, Tulsa Jansson, Maxime Desmarais-Tremblay, Asbjørn Aagaard Schmidt, and Ylwa Sjölin-Wirling.

Open Access This article is licensed under a Creative Commons Attribution 4.0 International License, which permits use, sharing, adaptation, distribution and reproduction in any medium or format, as long as you give appropriate credit to the original author(s) and the source, provide a link to the Creative Commons licence, and indicate if changes were made. The images or other third party material in this article are included in the article's Creative Commons licence, unless indicated otherwise in a credit line to the material. If material is not included in the article's Creative Commons licence and your intended use is not permitted by statutory regulation or exceeds the permitted use, you will need to obtain permission directly from the copyright holder. To view a copy of this licence, visit http://creativecommons.org/licen ses/by/4.0/. 


\section{References}

Arras, John. 2007. The way we reason now: Reflective equilibrium in bioethics. In The Oxford handbook of bioethics, ed. B. Steinbock. Oxford: Oxford University Press.

Arras, John. 2016. Theory and bioethics. In The Stanford Encyclopedia of Philosophy (Winter 2016 Edition), ed. Edward N. Zalta. https://plato.stanford.edu/archives/win2016/entries/theory-bioethics/.

Baderin, Alice. 2017. Reflective equilibrium: Individual or public? Social Theory and Practice 43(1): 1-28.

Brink, David O. 1987. Rawlsian constructivism in moral theory. Canadian Journal of Philosophy 17(1): 71-90.

Brun, Georg. 2017. Conceptual re-engineering: From explication to reflective equilibrium, Synthese, online first, $1-30$.

Buckley, Michael. 2010. The structure of justification in political constructivism. Metaphilosophy 41(5): 669-689.

Cohen, G.A. 2008. Rescuing justice and equality. Cambridge: Harvard University Press.

Daniels, Norman. 1979. Wide reflective equilibrium and theory acceptance in ethics. Journal of Philosophy 76(5): 256-282.

Daniels, Norman. 1996. Justice and justification. Reflective equilibrium in theory and practice. Cambridge: Cambridge University Press.

Daniels, Norman. 2018. Reflective Equilibrium. In Stanford encyclopedia of philosophy (Fall 2018 Edition), ed. Edward N. Zalta. http://plato.stanford.edu/archives/fall2018/entries/reflective-equilibrium/.

Doorn, Neelke. 2009. A Rawlsian approach to distribute responsibilities in networks. Science and Engingeering Ethics 16(2): 221-249.

Ebertz, Roger P. 1993. Is reflective equilibrium a coherentist model? Canadian Journal of Philosophy 23(2): 193-214.

Erman, Eva, and Niklas Möller. 2013. Three failed charges against ideal theory. Social Theory \& Practice 39: 19-44.

Erman, Eva, and Niklas Möller. 2015. Practices and principles: On the methodological turn in political theory. Philosophy Compass 10(8): 533-546.

Fabre, Cécile. 2012. Cosmopolitan war. Oxford: Oxford University Press.

Finlayson, Lorna. 2017. With radicals like these, who needs conservatives? Doom, gloom, and realism in political theory. European Journal of Political Theory 16(3): 264-282.

James, Aaron. 2005. Constructing justice for existing practice: Rawls and the status quo. Philosophy \& Public Affairs 33: 281-316.

Korsgaard, Christine. 2003. Realism and constructivism in twentieth-century moral philosophy. Journal of Philosophical Research 28: 99-122.

List, Christian, and Laura Valentini. 2016. The methodology of political theory. In The Oxford handbook of philosophical methodology, ed. H. Cappelen, T. Szabó Gendler, and J. Hawthorne, 525-553. Oxford: Oxford University Press.

McMahan, Jeff. 2013. Moral Intuition. In The Blackwell guide to ethical theory, vol. 2, ed. H. LaFollette and I. Persson, 103-120. Malden: Blackwell.

Mills, Charles. 2005. "Ideal Theory" as ideology. Hypatia 20(3): 165-184.

Parfit, Derek. 2011. On what matters, vol. 1. Oxford: Oxford University Press.

Rawls, John. 1951. Outline of a decision procedure for ethics. The Philosophical Review 60(2): 177-197.

Rawls, John. 1974. The independence of moral theory. Proceedings and Addresses of the American Philosophical Association 48: 5-22.

Rawls, John. 1980. Kantian constructivism in moral theory. The Journal of Philosophy 77(9): 515-572.

Rawls, John. 1999. A theory of justice, rev ed. Cambridge: Harvard University Press.

Rawls, John. 2005. Political liberalism, exp ed. New York: Columbia University Press.

Ronzoni, Miriam, and Laura Valentini. 2008. On the meta-ethical status of constructivism: Reflections on G.A. Cohen's "Facts and Principles". Politics, Philosophy \& Economics 7(4): 403-422.

Sangiovanni, Andrea. 2008. Justice and the priority of politics to morality. Journal of Political Philosophy 16(2): 137-164.

Sangiovanni, Andrea. 2016. How practices matter. Journal of Political Philosophy 24(1): 3-23.

Scanlon, T.M. 2003. Rawls on justification. In The Cambridge companion to Rawls, ed. S. Freeman, 139167. Cambridge: Cambridge University Press.

Singer, Peter. 2011. Practical ethics. Cambridge: Cambridge University Press. 
Street, Sharon. 2008. Constructivism about reasons. In Oxford studies in metaethics, vol. 3, ed. Russ ShaferLandau. Oxford: Clarendon Press.

Van Thiel, Ghislaine J.M.W., and Van Delden, Johannes J.M. 2010. Reflective equilibrium as a normative empirical model. Ethical Perspectives 17(2): 183-202.

Walden, Kenneth. 2012. In defense of reflective equilibrium. Philosophical Studies 166(2): 243-256.

Williams, Bernard. 2005. In the beginning was the deed: Realism and moralism in political argument, ed. Geoffrey Hawthorn. Oxford: Oxford University Press.

Wolff, Jonathan, and Avner de-Shalit. 2007. Disadvantage. Oxford: Oxford University Press.

Johan Brännmark, Eric Brandstedt, (2019) Rawlsian Constructivism and the Assumption of Disunity. Journal of Political Philosophy 27 (1):48-66.

Publisher's Note Springer Nature remains neutral with regard to jurisdictional claims in published maps and institutional affiliations. 